\title{
Time course of physiological response of $U$ IVa rotundata to growth irradiance transitions
}

\author{
William J. Henley, J. Ramus \\ Marine Laboratory and Department of Botany, Duke University, Beaufort, North Carolina 28516, USA
}

\begin{abstract}
A.BSTRACT: A vegetative clone of the macroalga Ulva rotundata was subjected to changes in irradiance $\left(9,29\right.$ and $\left.100 \% I_{0}\right)$ in an outdoor continuous flow system under nutrient-sufficient conditions. Growth rate, chlorophyll and starch content, respiration and photosynthesis were determined for $5 \mathrm{~d}$ following changes in irradiance. Starch reserves were highly dynamic, covering the complete range of observed values (about 0.3 to $3.5 \mathrm{mg} \mathrm{g}^{-1}$ dry weight) within $1 \mathrm{~d}$ following 9 to $100 \%$ or 100 to $9 \% \mathrm{I}_{\circ}$ transfers. Respiration decreased to the new level within $1 \mathrm{~d}$ following downward irradiance transfers (DT), but accelerated over several days after upward irradiance transfers (UT). Photosynthetic capacity $\left(\mathrm{P}_{\mathrm{m}}\right)$ exhibited little change for $5 \mathrm{~d}$ after DT, but increased steadily over the same period following UT. Chlorophyll changes were more gradual, requiring 4 to $5 \mathrm{~d}$ for complete recovery following the 100 to $9 \%$ and 9 to $100 \% \mathrm{I}_{0}$ transfers. Specific growth rate $(\mu)$ expressed on fresh (FW) and dry weight (DW) bases gradually increased over several days following UT, in agreement with $P_{m}$ data. Downward irradiance transfer resulted in a $1 \mathrm{~d}$ uncoupling of $\mu_{\mathrm{FW}}$ and $\mu_{\mathrm{DW}} ; \mu_{\mathrm{FW}}$ remained at a high level (perhaps cell division was fueled by mobilized starch reserves) while $\mu_{\text {Dw }}$ dropped off sharply, presumably due to low photosynthesis at the reduced irradiance. Results indicated that $U$. rotundata makes efficient use of variable irradiance by positioning at an intermediate state of acclimation due to appropriate rates of physiological response.
\end{abstract}

\section{INTRODUCTION}

Light is an essential and highly variable resource for macroalgal growth. Quantum irradiance in the intertidal environment fluctuates on a variety of time scales, ranging from seconds or less due to sunflecks (Dera \& Gordon 1968) to the seasonal daylength cycle. For a seaweed in a fixed position in the intertidal zone, the challenge is to optimize the use of variable irradiance. Implicit in this discussion are the assumptions that irradiance is at least sometimes limiting and that selection acts to increase algal growth rate.

Because there are inherent constraints on the capacity and rate of photoacclimation in algae (Henley \& Ramus 1989b) it follows that perfect acclimation to the instantaneous irradiance may be maladaptive. The only certain short-term features of the intertidal irradiance regime are that night and day will alternate regularly and that neither full sunlight nor severe shade conditions will persist. Intertidal macroalgae may be expected to adjust the composition of their photosynthetic apparatus for maximum 'long-term' benefit.
To predict the response of an alga to the complex natural irradiance regime, it is necessary to know: (1) the limits of physiological acclimation under extreme steady state irradiance, (2) the extent to which the alga responds to periodicity of change in irradiance, and (3) the rate of response to irradiance perturbations of various magnitudes. The first two of these features have been addressed for the chlorophyte Ulva rotundata (Henley \& Ramus 1989a, b, c). Here we describe the rate of response of growth rate, chlorophyll and starch content, respiration and photosynthetic rates of $U$. rotundata to sustained upward and downward transitions in irradiance.

\section{MATERIALS AND METHODS}

A vegetative clone of Ulva sp. (probably $U$. rotundata Blid.) from the vicinity of Beaufort, North Carolina, USA, and designated 7/86 based on its date of collection, was maintained in sparged outdoor continuousflow tanks. Further details of culture conditions are given in Henley \& Ramus (1989a). The experiments 
described in this paper were performed in October 1987, using ambient seawater continuously enriched to about $10 \mu M$ ammonium and $0.7 \mu M$ phosphate. Daily high seawater temperatures in the tanks ranged from 20.5 to $25.5^{\circ} \mathrm{C}$, and lows were 18 to $21.5^{\circ} \mathrm{C}$. This is around the temperature optimum for growth of $U$. rotundata, although growth rates are lower than in spring at the same temperature due to the ca $2 \mathrm{~h}$ difference in daylength.

Plants were preconditioned for at least $1 \mathrm{wk}$ at 100 , 29 and $9 \%$ relative $I_{0}$ (midday maxima of about 3400 , 1150 and $350 \mu \mathrm{mol} \mathrm{m} \mathrm{m}^{-2} \mathrm{~s}^{-1}$ ), controlled by 0,2 or 4 nylon screens over the tanks. One-time reciprocal transfers between the 3 irradiance pretreatments were then performed by changing the number of screens on the tanks after sunset. The time courses of growth rate, chlorophyll content, and the photosynthesis-irradiance (P-I) relationship were determined on a daily basis for $5 \mathrm{~d}$ after the transfers. Irradiance was measured with a LiCor LI-193SA spherical quantum sensor and recorded as 10 min mean with a LI-1000 data logger. Days 0, 1, 3 and 4 were virtually cloudless, with integrated daily irradiation (measured in air near the tanks) of $86 \pm 1 \mathrm{~mol} \mathrm{~m}^{-2}$. Day 2 became overcast mid afternoon and had an integrated irradiation of $69 \mathrm{~mol} \mathrm{~m}^{-2}$. Day 5 was mostly sunny with high, thin clouds and an integrated irradiation of $83 \mathrm{~mol} \mathrm{~m}^{-2}$

A followup experiment was performed to assess the P-I characteristics for Ulva rotundata oscillating intra( $3 \mathrm{~h}$ periodicity) or interday between 100 and $9 \% \mathrm{I}_{0}$. Plants were preconditioned at these 2 regimes as well as at 100,55 and $9 \%$ steady state $I_{0}$ and the P-I parameters were determined on 2 consecutive days for the 5 treatments.

Growth rates were determined as $1 \mathrm{~d}$ change in biomass. The entire biomass of each tank was harvested daily after sunset. Surface water was removed by rotation for $30 \mathrm{~s}$ in a 'salad spinner'. Fresh weight (FW) was determined to the nearest $0.1 \mathrm{~g}$. Each tank was restocked with 9 to $13 \mathrm{~g}$ of tissue. Surplus biomass was frozen and later lyophilized to determine the thallus solids (i.e. dry weight[DW]/FW) content. Specific growth rates $(\mu)$ are reported as integrated FW and DW changes $\left(\% \mathrm{~d}^{-1}\right)$ :

$$
\mu=100\left(W_{d+1}-W_{d}\right) / W_{d}
$$

where $W_{d}$ and $W_{d+1}$ are the weights on consecutive days.

Lyophilized samples for chlorophyll analysis were weighed, then briefly (about 1 min) rehydrated, immediately immersed in 5 or $10 \mathrm{ml}$ of $\mathrm{N}, \mathrm{N}$-dimethylformamide (DMF), and extracted in darkness at room temperature overnight. Absorbance values at 664 and $647 \mathrm{~nm}$, both corrected for scattering by subtraction of the absorbance at $700 \mathrm{~nm}$, were used with the equa- tions of Moran (1982) to calculate the concentrations of chlorophyll (chl) a and $b$, normalized to DW.

Lyophilized material was also subsampled for starch analysis. Weighed tissue was incubated for $6 \mathrm{~h}$ in $5 \mathrm{ml}$ of $60 \mathrm{mM} \mathrm{KH} \mathrm{PO}_{4}$ (Rosenberg 1981) at 95 to $100^{\circ} \mathrm{C}$. After cooling to room temperature, $2.5 \mathrm{ml}$ of $\mathrm{I}_{2} / \mathrm{KI}$ reagent (Shuster \& Gifford 1962) was added to each extract, and the absorbance at $\lambda_{\max }=560 \mathrm{~nm}$ was read promptly. Soluble potato starch was used as the standard $\left(\lambda_{\max }=590\right.$ to $600 \mathrm{~nm}$ in this system). Due to the $\lambda_{\text {max }}$ difference between the 2 starches, our Ulva rotundata values should be considered relative rather than absolute.

Discs (about $7 \mathrm{~cm}^{2}$ ) for photosynthesis measurements were cut shortly before sunset, for use on the following day. This reduced the risk of wound effects on photosynthesis measurements. One or two discs were incubated in $0.3 \mathrm{I} \mathrm{BOD}$ bottles for ca $20 \mathrm{~min}$ to $2 \mathrm{~h}$, depending on the incubation irradiance. Bottles were filled before each incubation from a reservoir of fresh, coarsely filtered seawater. They were continuously stirred by means of magnetic stir bars turned by waterdriven turbines. Turbulence served to reduce the unstirred boundary layer and kept the tissue discs suspended in the light field. The light source was a $1000 \mathrm{~W}$ narrow beam quartz halogen lamp. Infrared radiation was attenuated through $0.6 \mathrm{~m}$ of water, and the beam was dispersed somewhat by 2 layers of dimpled plastic and 1 layer of dimpled glass. Bottles were incubated in a flowing tapwater bath at $21 \pm 0.5 \mathrm{C}^{\circ}$. Attenuation was achieved both by increasing distance from the lamp and by nylon screens.

For each treatment, the P-I relationship was determined once daily, using 5 irradiances and a dark bottle. Time constraints precluded replicate incubations. Preliminary measurements indicated that the average coefficient of variation for triplicate incubations was about $10 \%$. All incubations were commenced at least $1.25 \mathrm{~h}$ after sunrise, at which time irradiance in the tanks was about half of the midday maximum.

Net $\mathrm{O}_{2}$ exchange rates were estimated from initial and final $\mathrm{O}_{2}$ concentrations, measured with a polarographic electrode and YSI model 57 oxygen meter. Initial $\mathrm{O}_{2}$ concentrations were $7 \pm 0.4 \mathrm{mg} \mathrm{l}^{-1}$ (range), and generally the change during incubations did not exceed $2 \mathrm{mg} \mathrm{l}^{-1}$. Neither duration of incubation nor time of day were found to affect photosynthetic rates (data not shown). For internal consistency, the 100, 29 and $9 \% \mathrm{I}_{0}$ controls were always incubated together in the morning, the 3 upward irradiance transitions around midday, and the 3 downward irradiance transitions in the afternoon. This arrangement permitted the irradiance-transferred plants to be exposed to maximum irradiance before incubation, which we consider especially important on the first day at the new 
irradiance. After incubation, all discs were frozen and later lyophilized for dry weight and chl determinations. Light-saturated photosynthesis rates $\left(\mathrm{P}_{\mathrm{m}}\right)$ were taken as the value at the highest irradiance (about $2000 \mu \mathrm{mol}$ $\mathrm{m}^{-2} \mathrm{~s}^{-1}$ ). In cases where this value was slightly lower than at the next lower irradiance, the 2 values were averaged to obtain $P_{m}$.

\section{RESULTS}

In response to upward irradiance transitions, $\mu$ required several days to attain the new higher $\mu$ observed in the steady state controls, but there was a steady trend only in the largest transition, i.e. 9 to $100 \% \mathrm{I}_{\mathrm{o}}$ (Fig. 1). The $\mu_{\mathrm{DW}}$ and $\mu_{\mathrm{FW}}$ were also closely

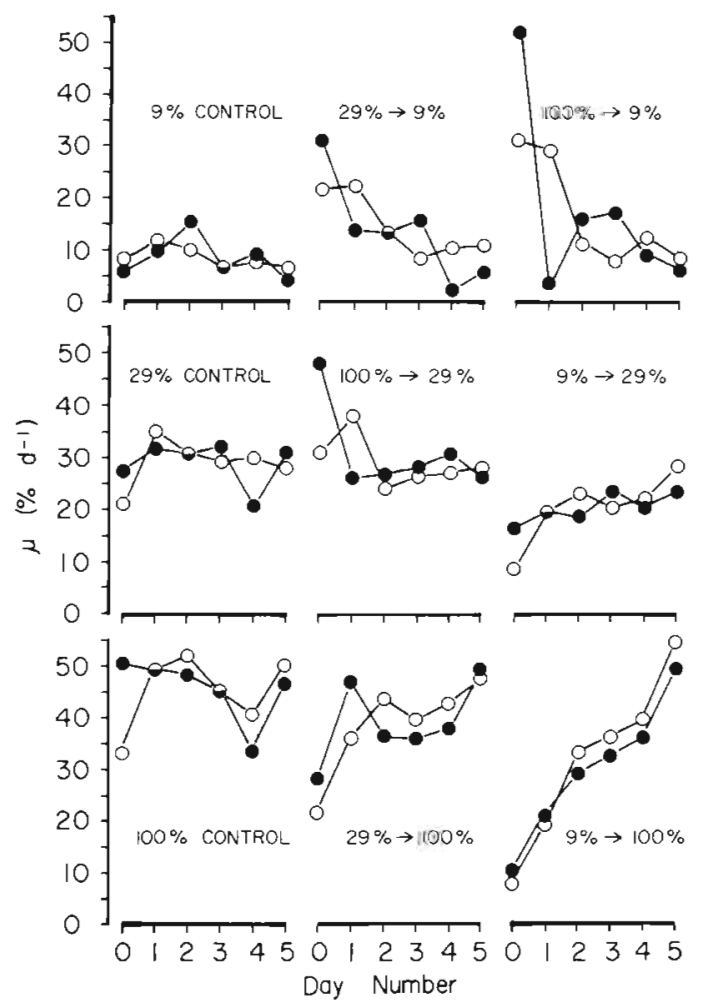

Fig. 1. Ulva rotundata. Daily specific growth rates on fresh (0) and dry weight $\bullet$ bases, following irradiance transitions compared to controls. Controls held at the indicated relative irradiance throughout the experiment. Others preconditioned at the first irradiance through Day 0 , then exposed to the second irradiance Days 1 to 5

matched only in the 9 to $100 \% \mathrm{I}_{0}$ transfer. In the downward irradiance transitions, $\mu_{F W}$ exhibited a $1 \mathrm{~d}$ lag before reaching the new level over 1 to $2 \mathrm{~d}$. In contrast, $\mu_{\mathrm{D} w}$ dropped markedly on the first day, then fluctuated for several days (Fig. 1). In general, $\mu_{\mathrm{FW}}$ and $\mu_{\mathrm{D} w}$ were poorly matched in the downward irradiance transitions.
Chl $(a+b)$ levels exhibited trends over time, although not continuous in some of the smaller transitions, e.g. 29 to $9 \% I_{0}$ (Fig. 2). For the largest transfers, between 100 and $9 \% \mathrm{I}_{0}, 4$ to $5 \mathrm{~d}$ were required for chl content to fully acclimate. Mass balance calculations of total chl

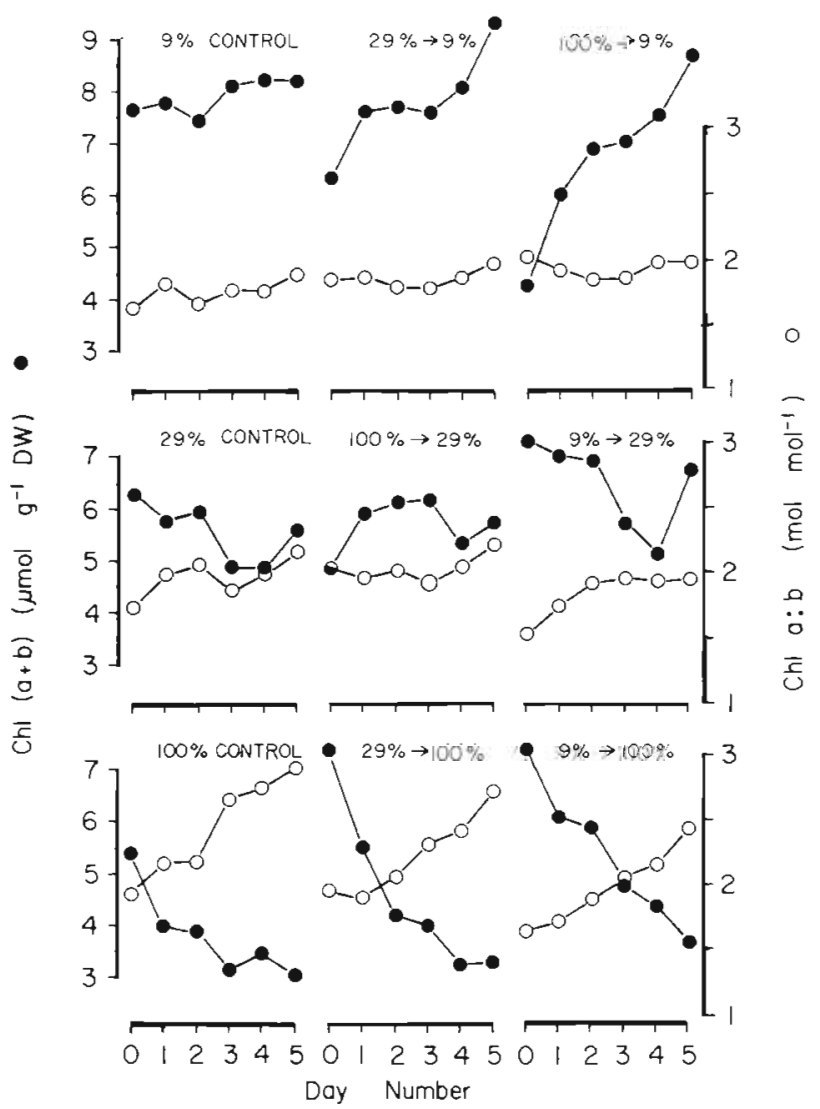

Fig. 2. Ulva rotundata. Total chlorophyll on a DW basis (•) and chl $a: b$ ratio (o) following irradiance transitions compared to controls. Treatments as in Fig. 1

$(a+b)$ per tank during the first day of irradiance transitions show that net chl synthesis continued in all treatments except for the 9 to $100 \% I_{0}$ transfer, where there was negligible change in chl biomass (data not shown). After the first day, considerable net chl synthesis resumed.

Chl $a: b$ ratios changed over time in both transferred and control plants (Fig. 2), so trends could not be ascribed to an effect of irradiance transfer. The unusually low initial chl $a: b$ ratio and high initial chl $(a+b)$ in $100 \% \mathrm{I}_{\circ}$ control plants were a consequence of heavy cloudcover on the day before the onset of the experiment. The chl $a: b$ ratio continued to rise in the $100 \% I_{0}$ controls throughout the remainder of the experiment, even after the chl $(a+b)$ had apparently stabilized. This unintended interference from natural irradiance variation confounded the experiment, but it also demonstrated that the sorts of pigment changes resulting from 
artificial irradiance manipulations really do occur in response to natural irradiance changes. Indeed, the slight anomalies in the chl content trends between Days 1 and 2 in the 100 and $29 \%$ controls and in the upward irradiance transitions coincided with overcast conditions which developed in the midafternoon on Day 2. This further demonstrated the effect of natural irradiance variation on pigment content.

The inverse nonlinear relationship between chl $(a+b)$ and chl $a: b$ which was previously observed under steady state conditions in Ulva rotundata (Henley \& Ramus 1989b) also seems to hold up following irradiance transfer (Fig. 3), indicating that a tightly

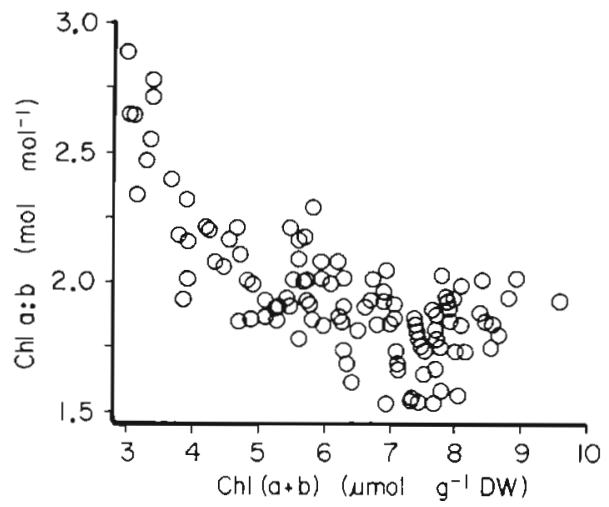

Fig. 3. Ulva rotundata. Scatter plot of $c h l a: b$ ratio vs total chl for all 9 treatments combined

regulated sequence of qualitative and quantitative changes in the light harvesting apparatus occurred during the acclimation process.

Starch concentration ranged from $<1 \%$ of DW in $9 \% \mathrm{I}_{0}$ plants to $3 \%$ of $\mathrm{DW}$ in $100 \% \mathrm{I}_{0}$ Ulva rotundata (Fig. 4). A drop in starch content on Day 2 in the $100 \%$ $\mathrm{I}_{\mathrm{o}}$ control may reflect afternoon cloudiness. Following either upward or downward irradiance transfers, starch content reached its new level within $1 \mathrm{~d}$. Some overshoot of the eventual new steady state (i.e. control) level was evident following all 3 downward irradiance transfers and the 9 to $29 \% \mathrm{I}_{0}$ transfer. After $5 \mathrm{~d}$, thalli transferred to $9 \% \mathrm{I}_{\circ}$ from either 29 or $100 \% \mathrm{I}_{\mathrm{o}}$ still contained less starch than the $9 \% \mathrm{I}_{\mathrm{o}}$ control. Eventually, the specific synthesis rate of starch must temporarily exceed $\mu$ at $9 \% \mathrm{I}_{\mathrm{o}}$ until the stable (9\% control) concentration $(0.7$ to $1 \%$ of DW) is achieved.

In Ulva rotundata controls grown at $9 \% \mathrm{I}_{\mathrm{O}}$, the mean $P_{m}$ was reduced by about $42 \%$ relative to the $100 \% I_{0}$ value, but there was only a $10 \%$ decrease in $\mathrm{P}_{\mathrm{m}}$ at $29 \%$ $I_{\circ}$ (Fig. 5). The mean dark respiration rate $\left(R_{d}\right)$ was 2 fold greater at $100 \%$ than at $9 \% I_{0}$ and was intermediate at $29 \% \mathrm{I}_{0}$ (Fig. 5).

Following downward irradiance transitions, $P_{m}$ showed no apparent trend over the $5 \mathrm{~d}$ of measurement

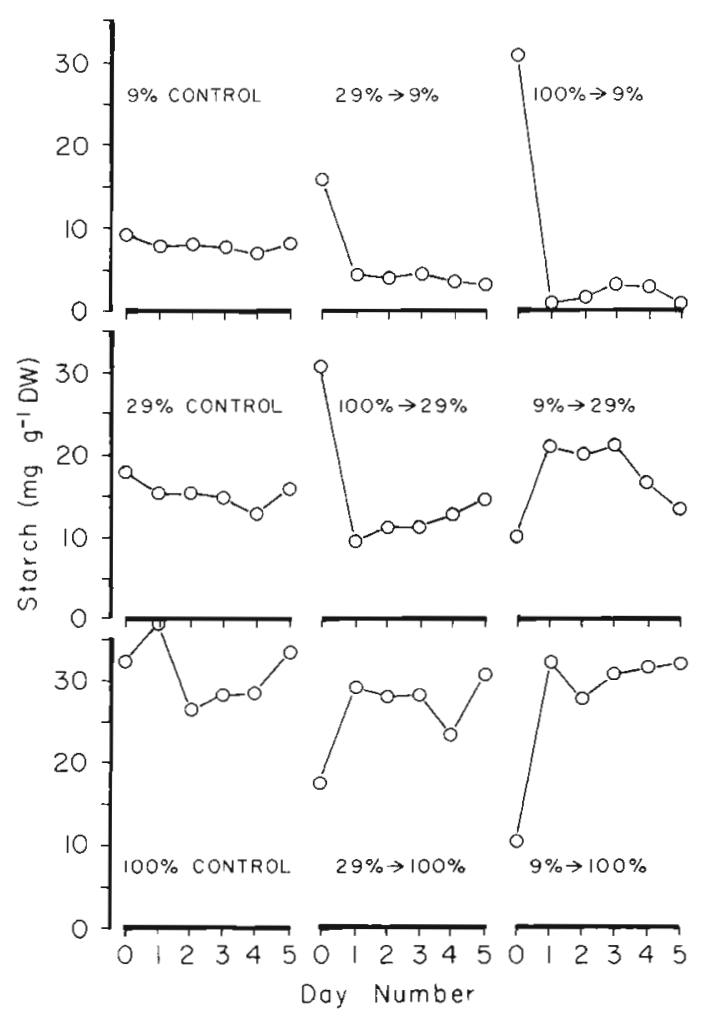

Fig. 4. Ulva rotundata. Starch concentration following irradiance transitions compared to controls. Treatments as in Fig. 1

(Fig. 5). $\mathrm{R}_{\mathrm{d}}$ changed appreciably only on the first day after the $100 \%$ to $9 \% \mathrm{I}_{\circ}$ transfer and thereafter levelled off (Fig. 5). It cannot be determined if the same occurred in the other 2 downward irradiance transfers because the Day 0 values were anomalously low. All 3 upward irradiance transitions elicited a net increasing trend in $\mathrm{P}_{\mathrm{m}}$ and $\mathrm{R}_{\mathrm{d}}$ over a $5 \mathrm{~d}$ period (Fig. 5).

Following irradiance transitions, $\mu$ and chl exhibited an inverse linear relation when all treatments were combined (Fig. 6). This was true whether $\mu$ and chl were normalized to FW $(n=36, r=-0.87, t=-10.3$, $p<0.001)$ or DW $(n=36, r=-0.84, t=-9.0, p<0.001)$. Only one point, corresponding to the first day of the $100 \%$ to $9 \% I_{0}$ transition, noticeably deviated from this pattern, and only when expressed on a DW basis.

Ulva rotundata exposed to 9 and $100 \% \mathrm{I}_{0}$ on alternate days grew at the same rate as 9 and $100 \% I_{0}$ control plants, but slower on average than plants under steady state light of the same average daily flux, i.e. $55 \% \mathrm{I}_{\circ}$ (Table 1 ). Likewise, $U$. rotundata under intraday $9 / 100 \% \mathrm{I}_{0}$ fluctuations grew at a rate midway between those of the 9 and $100 \%$ controls and less than the $55 \%$ $I_{0}$ control (Table 1), as found previously for a variety of intraday oscillation periodicities (Henley \& Ramus $1989 \mathrm{c})$. The average $\mu$ for plants oscillating either intraor interday were identical. Fluctuating irradiance 


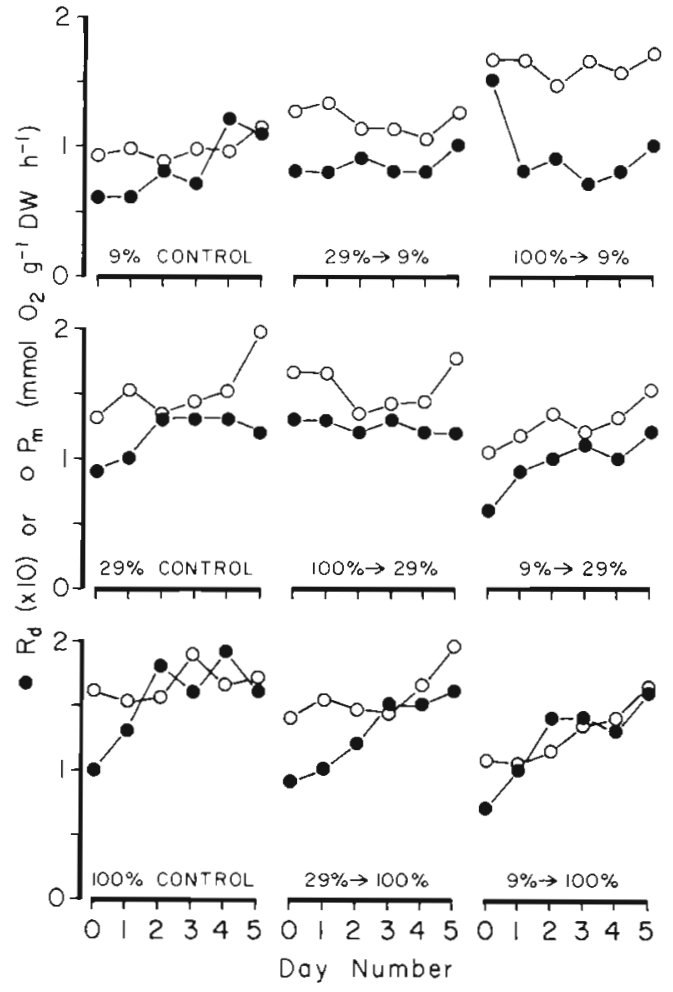

Fig. 5. Ulva rotundata. $P_{m}(0)$ and $R_{d}(\bullet)$ following irradiance transitions compared to controls. Treatments as in Fig. 1. In the $100 \%$ control and the 100 to $9 \%$ and 100 to $29 \% \mathrm{I}_{0}$ transfers, the Day $0 \mathrm{P}_{\mathrm{m}}$ values were set equal to the mean (Days 1 to 5 ) of the $100 \% I_{0}$ control because the observed values were anomalously low ( $>2$ standard deviations from the control mean)

regimes elicited $\mathrm{P}_{\mathrm{m}}$ values which were not appreciably lower than that of $100 \% \mathrm{I}_{\mathrm{o}}$ controls (Table 1). Intraday oscillating plants respired at about the same rate as $55 \% \mathrm{I}_{\circ}$ plants, whereas interday alternating plants varied $R_{d}$ depending on which irradiance they were exposed to on that particular day (Table 1).

\section{DISCUSSION}

Assuming, based on its intertidal origin, that Ulva rotundata clone 7/86 is a high-light species or ecotype, it is unlikely that it would ever experience more than several consecutive days of extreme shade due to cloud cover and/or very turbid water. The acclimation process may therefore rarely go to completion so that the important aspect of the acclimation response may be the lag time and the initial rate of adjustment. Unless the response time approximately matches the periodicity of irradiance fluctuations, the response is unlikely to be beneficial. Insofar as more photosynthesis may be carried out during brief exposures to high irradiance than during long exposures to low irradiance, rapid loss

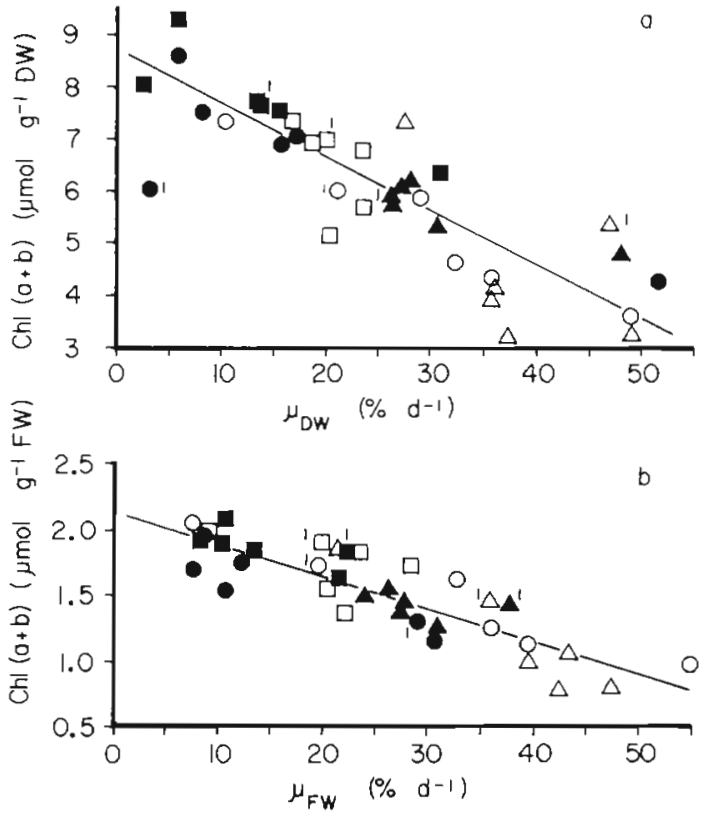

Fig. 6. Ulva rotundata. Scatter plot of total chl vs (a) $\mu_{\mathrm{DW}}$ and (b) $\mu_{\mathrm{FW}}$ for irradiance transfer treatments. Lines indicate axes of least squares correlation. ' 1 ' next to certain symbols denotes values for Day 1 , which are not significantly correlated when considered alone. Open symbols, upward $\mathrm{I}_{0}$ transfers; filled symbols, downward $I_{0}$ transfers. Circles: $9 / 100 \%$ reciprocal transfers; squares: $9 / 29 \%$ reciprocal transfers; triangles: $29 / 100 \%$ reciprocal transfers

Table 1. Growth rate $(\mu)$, light-saturated photosynthesis rate $\left(\mathrm{P}_{\mathrm{m}}\right)$ and mean dark respiration rate $\left(\mathrm{R}_{\mathrm{d}}\right)\left(\mathrm{mmol} \mathrm{O} \mathrm{O}_{2} \mathrm{~g}^{-1} \mathrm{~h}^{-1}\right)$ under steady state vs fluctuating irradiance. Values are $2 \mathrm{~d}$ means. $\bar{\mu}$ is 3 d mean $\pm \mathrm{SD}$

\begin{tabular}{|lccr|}
\hline Regime & $\mathrm{P}_{\mathrm{m}}$ & $\mathrm{R}_{\mathrm{d}}$ & \multicolumn{1}{c|}{$\vec{\mu}$} \\
\hline $9 \%$ control & 1.5 & 0.06 & $9.9 \pm 8.0$ \\
$55 \%$ control & 2.1 & 0.11 & $42.0 \pm 3.6$ \\
$100 \%$ control & 2.0 & 0.12 & $46.6 \pm 3.7$ \\
$9 / 100 \%$ intraday & 2.0 & 0.10 & $26.9 \pm 4.2$ \\
$9 / 100 \%$ interday & & & \\
$9 \%$ days & 1.8 & 0.08 & $9.5 \pm 5.8$ \\
$100 \%$ days & 1.9 & 0.11 & $45.9 \pm 1.9$ \\
\hline
\end{tabular}

of photosynthetic capacity under low irradiance conditions would be counterproductive, and may serve only as a means to reduce the capital metabolic costs (sensu Richardson et al. 1983) in response to prolonged subsaturating light. Indeed, the daily $\mu$ under interday irradiance fluctuations matches that in the respective nonfluctuating controls (Table 1 ). Combined with the observations that $29 \% \mathrm{I}_{\mathrm{o}}$ acclimated $U$. rotundata has only a slightly lower mean $\mathrm{P}_{\mathrm{m}}$ than $100 \% \mathrm{I}_{\mathrm{o}}$ plants, grows well at all irradiances and has the highest photon growth yield (Henley \& Ramus 1989a,b), this indicates that $U$. rotundata can make the best use of 
variable irradiance by attaining an intermediate state of photoacclimation by means of appropriate rates of response.

Ulva rotundata $7 / 86$ transferred from $100 \%$ to $9 \% \mathrm{I}_{0}$ did not appreciably reduce $\mathrm{P}_{\mathrm{m}}$ over a $5 \mathrm{~d}$ period. The reciprocal transfer resulted in a continuous increase in $\mathrm{P}_{\mathrm{m}}$ over the same time period, indicating a faster acclimation of photosynthetic capacity to increasing irradiance than to decreasing irradiance. $U$. rotundata which has been at low irradiance for 4 to $5 \mathrm{~d}$ may contain the same amount of pigment as plants shaded for several weeks (Fig. 2). However, because only prolonged $(>5 d)$ exposure to $9 \% I_{0}$ leads to a reduction in $P_{m}$, the former may temporarily outperform the latter upon return to high irradiance because of a difference in $P_{m}$.

Our respiration data also support the idea that Ulva rotundata grows most efficiently when acclimated to intermediate irradiance. The absolute $R_{d}$ is positively correlated with steady state irradiance in $U$. rotundata (Fig. 5), consistent with the pattern observed in phytoplankton (e.g. Falkowski et al. 1985) and other seaweeds (e.g. Lapointe et al. 1984). However, respiration becomes relatively more important at $9 \% I_{0}$. The ratio of respiration to potential maximum gross photosynthesis, i.e. $R_{d} /\left(P_{m}+R_{d}\right)$, is $0.076,0.068$ and 0.083 for 9,29 and $100 \% I_{o}$ plants, respectively. The actual $R_{d} /$ $\left(\mathrm{P}_{\mathrm{m}}+\mathrm{R}_{\mathrm{d}}\right)$ for the $9 \% \mathrm{I}_{\circ}$ plants is closer to 0.10 because the $9 \% \mathrm{I}_{0}$ plants are below saturating irradiance throughout the day. Similarly, integrated nocturnal $R_{d}$ assuming it occurs at a rate equal to that measured during the day, consumes about $27,15.4$ and $16.2 \%$ of diurnal net production for 9, 29 and $100 \% I_{0}$ plants, respectively. Thus, the relative respiratory burden is greatest for $9 \% \mathrm{I}_{\circ}$ plants and least for $29 \% \mathrm{I}_{0}$ plants, in agreement with the pattern of relative photon growth yield (Henley \& Ramus 1989b).

The starch, $\mu_{\mathrm{Fw}}$ and $\mu_{\mathrm{DW}}$ data (Figs. 1 and 4 ) together suggest that the highly dynamic starch pool can sustain a high rate of cell expansion and/or division for $1 \mathrm{~d}$ following downward irradiance transfers. The starch reserves are also rapidly replenished after upward irradiance transfers. The observed changes in starch may represent only concentration or there also could be a change in the ratio of components (e.g. amylose and amylopectin) having different $\mathrm{I}_{2} / \mathrm{KI}$ reactivities (Painter 1983, Guilbot \& Mercier 1985).

Lapointe \& Tenore (1981) reported a chl adjustment. time of about $3 \mathrm{~d}$ in Ulva fasciata. Similar chl photoacclimation rates have been observed in phytoplankton in either continuous light (Falkowski 1984, Geider et al. 1986) or a light-dark cycle (Rivkin et al. 1982, Post et al. 1984), although Lewis et al. (1984) reported times of less than $1 \mathrm{~d}$. Thus, the chl adjustment rate observed here in $U$. rotundata $7 / 86$ ( 4 to $5 \mathrm{~d}$ to completion) is comparable to that of the few other algae studied. Unlike $P_{m}$ and in contrast to model predictions (Geider \& Platt 1986), there was no strong evidence for different chl acclimation rates for the upward versus downward irradiance transfers in $U$. rotundata.

Geider \& Platt (1986) predicted that the rate constant (k) for chl photoacclimation is proportional to the magnitude of irradiance change. Inspection of the 29 to $100 \%$ and the 9 to $100 \% I_{0}$ transfers (Fig. 2) suggests that in $U$. rotundata the opposite may be true. The 29 to $100 \%$ transfer plants appear to decrease their chl content more rapidly than do the $9 \%$ to $100 \%$ plants. However, this is consistent with Geider \& Platt's assertion if one considers that, due to reduced $\mathrm{P}_{\mathrm{m}}$ in $9 \% \mathrm{I}_{0}$ conditioned plants, they grow more slowly upon transfer to saturating light than do plants initially acclimated to $29 \% \mathrm{I}_{\mathrm{o}}$. Indeed, the mean $\mu_{\mathrm{DW}}$ for $4 \mathrm{~d}$ following transfer to $100 \% \mathrm{I}_{0}$ was $39 \% \mathrm{~d}^{-1}$ for $29 \% \mathrm{I}_{\circ}$ acclimated plants vs $29.5 \% \mathrm{~d}^{-1}$ for $9 \% \mathrm{I}_{0}$ plants. In other words, $\mu$ determines the rate of chl dilution. However, it seems that it is the instantaneous $\mu$ which is important in governing $k_{1}$ as opposed to the eventual balanced $\mu$ at the new irradiance as suggested by Geider \& Platt (1986).

Large upward irradiance transitions (9 to 100\%) apparently caused cessation of net chl synthesis for $1 \mathrm{~d}$ and consequent dilution by continued growth. There was no net destruction of chl caused by upward transitions in irradiance, as found in both a dinoflagellate and diatoms (Prézelin \& Matlick 1980, Post et al. 1984, Geider et al. 1986), although we cannot rule out some photooxidation of chl which was compensated by replacement synthesis. After the first day following transfer, the decrease in chl $\mathrm{g}^{-1}$ DW cannot be explained simply by cessation of chl synthesis and dilution by growth. Rather, net synthesis of chl resumed but at a lesser rate than $\mu$ until a new steady state concentration was attained.

A linear $\mu$-chl relation was found during the course of photoacclimation (Fig. 6). This was also the case under a series of steady state irradiance (Falkowski 1980, Falkowski et al. 1985, Geider et al. 1985, Post et al. 1985, Geider \& Osborne 1986, Henley \& Ramus 1989b). Only plants experiencing a large downward irradiance transfer (e.g. 100 to $9 \%$, Fig. 6a) are unable to synthesize enough pigments in one day to compensate for the severe reduction in available light, hence leading to an anomalously low $u$. Considering each transition separately, the $\mu$-chl relation is less evident for some of the smaller magnitude irradiance transfers due to clustering or scattering of the points. Similarly, the relation is weak when only the values for the first day in each transition are considered (FW-normalized: $n=6, r=$ $-0.79, t=-2.6, p>0.05$; DW-normalized: $n=6, r=$ $-0.51, t=-1.2, p>0.2$ ). Taken together, these obser- 
vations indicate that $\mu$ and chl become uncoupled under conditions of variable irradiance, as observed in longer-term outdoor studies of Ulva spp. (Lapointe \& Tenore 1981, Duke et al. 1986). Nevertheless, there is a strong tendency toward a linear $\|$-chl relation, suggestive of a feedback regulation system which becomes temporarily overwhelmed following large irradiance changes.

Acknowledgements. This research was conducted in partial fulfillment of the requirements for the Ph. D. degree (WJH) in the Department of Botany, Duke University. Funding was provided by 2 Sigma Xi Grants-in-Aid of Research to W. J. H

\section{LITERATURE CITED}

Dera, J., Gordon, H. R. (1968). Light field fluctuations in the photic zone. Limnol. Oceanogr 13: 697-699

Duke, C. S., Lapointe, B. E., Ramus, J. (1986). Effects of light on growth, RuBPCase activity and chemical composition of Ulva species (Chlorophyta). J. Phycol. 22: 362-370

Falkowski, P. G. (1980). Light-shade adaptation in marine phytoplankton. In: Falkowski, P. G. (ed.) Primary productivity in the sea. Plenum Press, New York, p. 99-119

Falkowski, P. G. (1984). Kinetics of adaptation to irradiance in Dunaliella tertiolecta. Photosynthetica 18: 62-68

Falkowski, P. G., Dubinsky, Z., Wyman, K. (1985). Growthirradiance relationships in phytoplankton. Limnol. Oceanogr. 30: 311-321

Geider, R. J., Osborne, B. A. (1986). Light absorption, photosynthesis and growth of Nannochloris atomus in nutrientsaturated cultures. Mar. Biol. 93: 351-360

Gejder, R. J., Osborne, B. A., Raven, J. A. (1985). Light dependence of growth and photosynthesis Phaeodactylum tricornutum (Bacillariophyceae). J. Phycol. 21: 609-619

Geider, R. J., Osborne, B. A., Raven, J. A. (1986). Growth, photosynthesis and maintenance metabolic cost in the diatom Phaeodactylum tricornutum at very low light levels. J. Phycol, 22: 39-48

Geider, R. J., Platt, T (1986). A mechanistic model of photoadaptation in microalgae. Mar. Ecol. Prog. Ser. 30: 85-92

Guilbot, A., Mercier, C. (1985). Starch. In: Aspinall, G. O (ed.) The polysaccharides, Vol.3. Academic Press, Orlando, p. $209-282$

Henley, W. J., Ramus, J. (1989a). Photoacclimation of Ulva rotundata (Chlorophyta) under natural iradiance. Mar. Biol. (in press)

This article was presented by Dr M. J. Dring, Belfast, N. Ireland
Henley, W. J., Ramus, J. (1989b). Optimization of pigment content and the limits of photoacclimation for Ulva rotundata (Chlorophyta). Mar. Biol. (in press)

Henley, W. J., Ramus, J. (1989c). Photoacclimation and growth rate responses of Ulva rotundata (Chlorophyta) to intraday variations in growth irradiance. J. Phycol. 25: 398-401

Lapointe, B. E., Tenore, K. R. (1981). Experimental outdoor studies with Ulva fasciata Delile. I. Interaction of light and nitrogen on nutrient uptake, growth, and biochemical composition. J. exp. mar. Biol. Ecol. 53: 135-152

Lapointe, B. E., Tenore, K. R., Dawes, C. J. (1984). Interactions between light and temperature on the physiological ecology of Gracilaria tikvahiae (Gigartinales: Rhodophyta). I. Growth, photosynthesis and respiration. Mar Biol. 80: $161-170$

Lewis, M. R., Cullen, J. J., Platt, T. (1984). Relationships between vertical mixing and photoadaptation of phytoplankton: similarity criteria. Mar. Ecol. Prog. Ser. 15: $141-149$

Moran, R. (1982). Formulae for determination of chlorophyllous pigments extracted with $\mathrm{N}, \mathrm{N}$-dimethylformamide. Plant Physiol. 69: 1376-1381

Painter, T J. (1983). Algal polysaccharides. In: Aspinall, G. O. (ed.) The polysaccharides, Vol.2. Academic Press, Orlando, p. 195-285

Post, A. F., Dubinsky, Z, Wyman, K., Falkowski, P. G. (1984) Kinetics of light-intensity adaptation in a marine plank. tonic diatom. Mar. Biol. 83: 231-238

Post, A. F., Dubinsky, Z, Wyman, K., Falkowski, P. G. (1985). Physiological responses of a marine planktonic diatom to transitions in growth irradiance. Mar. Ecol. Prog. Ser. 25 $141-149$

Prézelin, B. B., Matlick, H. A. (1980). Time-course of photoadaptation in the photosynthesis-irradiance relationship of a dinoflagellate exhibiting photosynthetic periodicity. Mar. Biol. 58: 85-96

Richardson, K., Beardall, J., Raven, J. (1983). Adaptation of unicellular algae to irradiance: an analysis of strategies. New Phytol. 93: 157-191

Rivkin, R. B., Seliger, H. H., Swift, E., Biggley, W. H. (1982). Light-shade adaptation by the oceanic dinoflagellates Pyrocystis noctiluca and $P$. fusiformis. Mar. Biol. 68: 181-191

Rosenberg, G. (1981). Ecological growth strategies in the seaweeds Gracilaria foliffera (Rhodophyceae) and Ulva sp. (Chlorophyceae). Ph. D. dissertation, Yale University, New Haven

Shuster, L., Gifford, R. H. (1962). Changes in 3'-nucleotidase during the germination of wheat embryos. Arch. Biochem. Biophys. 96: 534-540

Manuscript first received: October 4, 1988

Revised version accepted: February 24, 1989 